
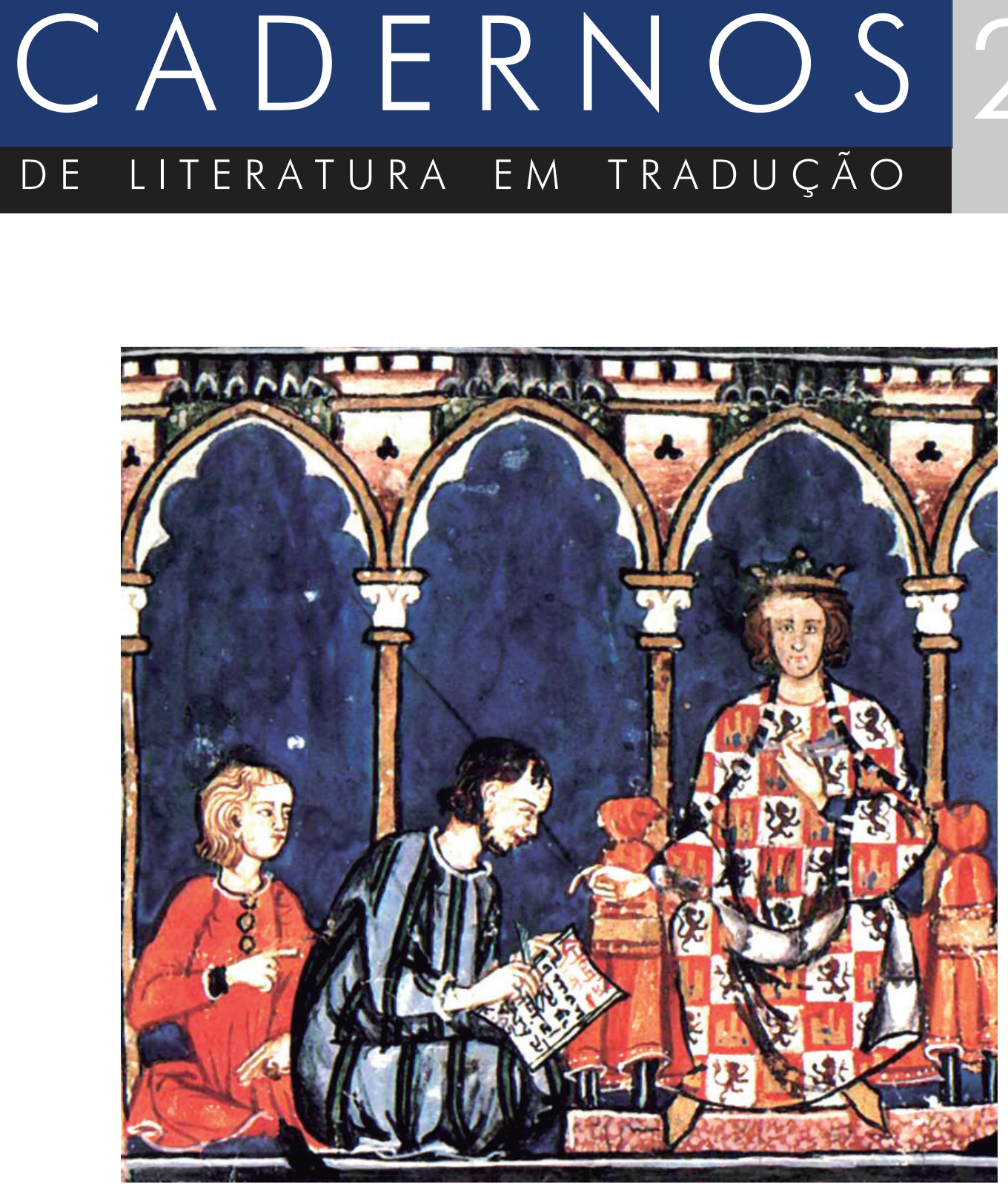

Tradutores da chamada Escola de Toledo com Afonso $X$ de Castela 


\title{
É hora! Dois poemas de Semion Nadson em tradução
}

\author{
Marina Darmaros ${ }^{1}$
}

Resumo: O poeta da Rússia Imperial Semion Nadson morreu com apenas 24 anos de idade e tem, como escreve Paulo Bezerra, um "legado contraditório". Inspirador de composições de Rachmaninoff e amado por antagonistas como Lênin e Búnin, ele foi massacrado por Mandelstam (que, no entanto, nunca deixava de relê-lo), Otto Maria Carpeaux e Tchukóvski.

Palavras-chave: Semion Nadson, literatura russa, poesia russa

\begin{abstract}
Semyon Nadson was a poet from Imperial Russia who died at the age of 24 and left a "contradictory legacy", according to Paulo Bezerra. He inspired Rachmaninoff's compositions and had Bunin's first published poem dedicated to him, but was criticized by Chukovsky and Mandelstam. Yet one thing is certain: he never stopped being read and mentioned by the Russians.
\end{abstract}

Keywords: Semyon Nadson, Russian literature, Russian poetry

Semion Nadson (1862-1887) foi um poeta da Rússia Imperial, filho de um oficial de origens judias cujo pai se converteu à Igreja Ortodoxa Grega ("The Poet of Despairing Hope," 1937, p. 681). Sua mãe era proveniente de uma família nobre que seguia a Igreja Ortodoxa Russa, mas caiu na desgraça com a morte do pai, quando Semion tinha apenas dois anos de idade. Assim, a mãe foi obrigada a obter recursos para sustentar os dois filhos trabalhando como empregada e professora

1 Marina Darmaros é doutora em Literatura e Cultura Russa pela Universidade de São Paulo e mestra em jornalismo internacional pela Universidade Estatal Russa da Amizade entre os Povos. E-mail: marinadarmaros@gmail.com 
particular. Quando o garoto tinha sete anos de idade, ela tentou melhorar a situação da família mudando-se de Kiev a Petersburgo, mas a pobreza se agravou ali: mesmo quando a mãe se casou pela segunda vez, o segundo marido logo cometeu suicídio e ela própria morreu de tuberculose quando Semion tinha apenas doze anos.

O menino já estava, porém, no Ginásio Militar n 2 , onde recebia educação paga pelo governo e pôde concluir ali os estudos. De compleição física fraca e com um estado psicológico abalado não sem razão, o garoto teve um desenvolvimento intelectual cedo na vida e lia muito. Em maio de 1878, aos dezesseis anos, Nadson publicou seu primeiro poema, no jornal Svet. Naquela época, ele também se apaixonou ensandecidamente por Natália Mikháilovna Dechevova, irmã de um colega de classe - mas ela também logo morreu de tuberculose, em 1879.

É a ela que ele dedica, mais tarde, seu livro de poemas e, em seu diário, escreve sobre Natália: "Após a morte, não temo a morte, mas não desejaria morrer a princípio; primeiro, devo trabalhar duro para ser digno dela; depois, devo trabalhar para os outros, devo tentar fazer sozinho o que nos preparávamos para fazer juntos. Eu tenho talento - tenho certeza disso - e, em nome dela, prometo não permitir uma única nota falsa e sem sinceridade em minhas canções, sequer uma palavra mercenária." (“The Poet of Despairing Hope," 1937, p. 682).

Naquele mesmo ano, Nadson terminava o ginásio e sua saúde começava a se deteriorar. No verão, ele foi enviado a Tblisi (atual capital da Geórgia), com os custos pagos pelo governo, para se recuperar. Mas o sul lhe desagradava tanto quanto o treinamento militar. No final das contas, de volta ao norte, ele escreve com tristeza, em setembro de 1882, sobre ter se tornado oficial: "Uma vida sem amigos, uma vida solitária se iniciou para mim, e meu coração está oprimido pelo medo no limiar dessa nova vida.” (Idem, p. 683). A partir de então ele ficou estacionado no Kronstadt, com o $148^{\circ}$ Regimento do Cáspio, sem qualquer amor ao mundo militar - mas não sem amigos.

No verão de 1883, ele sofreu de uma fístula tuberculosa em uma das pernas e conseguiu se curar, mas a vida, daí por diante, foi uma sucessão de doenças até a morte prematura. Na primavera de 1884, ele finalmente deixou o exército para se dedicar à literatura, mas logo os amigos o enviaram a Wiesbaden para tratar da saúde. Novamente ele flanou no exterior por um ano e retornou à Rússia no inverno de 1885. Sua saúde apenas piorava e, no outono de 1886, ele fez uma última viagem, a Ialta, na Crimeia. Com apoio do Fundo Literárioº ${ }^{2}$ ele conseguiu

2 Como escreve Mandelstam em O Rumor do Tempo (p. 46), o fundo posteriormente tornou-se detentor dos direitos de publicação de Nadson. 
publicar um volume de poemas, dedicado a Natália. Mas tudo isso aconteceu às custas de enormes esforços, que o deixaram esgotado ao chegar a Ialta. Assim, somado a ataques impiedosos da crítica no jornal Nôvoie vrêmia, piorou a tuberculose de Nadson, que atacou o cérebro, levando a sua morte, em 19 de janeiro de 1887. Seu corpo foi trasladado a Petersburgo e inúmeros literatos e amigos estiveram em seu funeral.

\section{Legado contraditório}

A definição de Nadson como proprietário de um "legado contraditório" por Paulo Bezerra (Mandelstam, 2019, p. 27), não se restringiu a suas qualidades literárias. Apesar de ser considerado um dos representantes da literatura russo-judia por historiógrafos desse ramo, como Vassíli Lvov-Rogatchevski, ele é excluído do rol por outros, como Zsuzsa Hetényi (2008): “O critério usado por Lvov-Rogatchevski é muito questionável. Ele lista Nadson entre os escritores russo-judeus, apesar de sua obra incluir apenas um único poema sobre um assunto judeu, enquanto não cita de maneira alguma Óssip Dimov, autor de diversas obras sobre assuntos judeus."

A morte precoce e a conversão duas gerações antes também parecem ter sido levadas em consideração por outros historiógrafos, como Friedberg (1984, p. 95): "Na Rússia, também o batismo foi frequentemente um bilhete de entrada à cultura majoritária. Diferentemente de Heine, porém, poetas como Semion Nadson, excepcionalmente popular em seus dias, geralmente davam de ombros aos assuntos judeus."

Bezerra (Mandelstam, 2019, p. 27), em nota explicativa a sua tradução de O rumor do tempo, de Mandelstam, porém, referia-se principalmente ao legado literário de Nadson: "Poeta judeu-russo com legado contraditório. Com sua poesia sentimental, Nadson conquistou, ainda em vida, a estima de um público enorme e o desprezo da crítica por gerações a seguir.” O próprio Mandelstam, no livro supracitado, não deixa de mencionar Nadson em tom cambaleante:

Mas quereis a chave dessa época, o livro incandescido de tanto contato, o livro que não queria morrer por nada nesse mundo e jazia como se estivesse vivo na sepultura estreita dos anos [mil oitocentos e] noventa, o livro cujas folhas amarelaram antes do tempo não se sabe se de tanta leitura ou se do sol dos bancos das dátchas, livro cuja primeira página revela os traços de um jovem com um penteado inspirado, traços que se tornaram icônicos? Ao olhar o rosto do eternamente jovem Nádson, fico maravilhado ao mesmo 
tempo com a verdadeira incandescência desses traços e com sua absoluta inexpressividade, com sua simplicidade quase campônia. Todo o livro dele não é assim? 'Toda a época não foi assim? Se o mandassem a Nice, se lhe mostrassem o Mediterrâneo, ele continuaria a cantar seu ideal e sua geração sofredora da mesma forma, talvez acrescentando uma gaivota e a crista de uma onda. Não riais do nadsonismo ${ }^{3}$; é um enigma da cultura russa e, no fundo, é incompreensível a sua sonoridade porque nós não entendemos e nem ouvimos como entendiam e ouviam eles. Quem é esse monge campônio com traços inexpressivos de eterno jovem, esse ídolo inspirado da juventude estudantil, precisamente da juventude estudantil, isto é, de uma gente escolhida em determinados séculos, esse profeta dos saraus colegiais? Quantas vezes, já sabendo que Nadson era ruim, ainda assim reli seu livro e, rejeitando a arrogância poética do presente e o ressentimento pela ignorância desse jovem no passado, procurei ouvir sua sonoridade como sua geração ouvia! Neste caso, como me ajudaram os diários e as cartas de Nadson; uma colheita literária contínua, as velas, os aplausos, as faces em chama; o círculo de sua geração e, no centro do altar, a mesinha de leitura com um copo d'água. Como insetos de verão sob o vidro de uma lâmpada quente, toda essa geração ardia e se consumia no fogo das festas literárias. (Mandelstam, 2019, p. 28-29)

Assim, como escreve a pesquisadora Elena Glazova Corrigan, é grande a dose de sátira na visão de Mandelstam, que ainda recorre diversas vezes à figura do poeta oitocentista na obra e o apresenta como

o grande vitorioso em uma empreitada marcada por seguidas perdas. Ele exercia notável controle sobre seu público. Mas o poder de sua voz imóvel e canhestra sobre a consciência ardente e viva de seus leitores é descrita como o suicídio do século, como a perda unânime do século de seu desejo de viver e o papel de Nadson como líder é satirizado de maneira mordaz. (GLAZOVA-CORRIGAN, 2000 p. 57)

Também Vladímir Maiakóvski menciona o poeta oitocentista em sua produção. No poema Incompreensível para as massas, escrito em 1927, por exemplo, o poeta da Revolução escreve:

3 Grifo meu. No original "nadsonovschina", que Bezerra verte de maneira muito apropriada com o sufixo "ismo" remetendo a "doença" - algo bastante cabível no caso de outras "schina", como a "iesseninschina” ligada ao poeta suicida Serguêi Iessiênin (1895-1925). 
Aonde

galopando

chega teu pensamento,

um deles

considera tudo

sonolento:

-Sou homem

de outra têmpera! Perdão,

lembra-me agora

um verso de Nadson...

(apud RIBEIRO, 2001, p. 56)

Em O Percevejo, um bombeiro criado pelo futurista clama ainda:

Um fogareiro ou um fogão

podem torrar sua casa

e você também, cidadão!

Incêndios são causados

por sonhos mal-sonhados,

por isso nunca leve

para ler na cama

Nadson e Járov!

(MAIAKÓVSKI, 2009, p. 42)

Quem o cita ainda é o psicólogo Lev Vigotski (1896-1934). Em Imaginação e criação na infância, ele reproduz os versos de Nadson sob uma luz positiva: "não há no mundo suplício maior que o suplício da palavra; inutilmente um grito quer sair, às vezes, da boca; inutilmente, o amor está pronto para queimar a alma: nossa língua pobre é fria e deplorável." (Vigotski, 2009 p. 55 apud DIAS, 2017 p. 10) Enquanto no texto Uriel Acosta - A Tempestade, sobre os versos do alemão Karl Ferdinand Gutzkow (1811-1878) acerca do filósofo suicida, um judeu português radicado em Amsterdã, remete uma montagem da peça a um "nadsonismo cênico" e um “clássico desmagnetizado”. (MARQUES, 2015 p. 230)

4 Agradeço a Letícia Mei, especialista em Maikóvski que me ajudou a localizar o trecho. 
Além disso, a primeira das obras publicadas do laureado com o Nobel Ivan Bunin (1870-1953) foi o poema Nad moguiloi S.Ia. Nadsona (Sobre o túmulo de Nadson, em metalinguagem com o poema de autoria de Nadson intitulado Sobre o túmulo de Turguêniev), de 1887, que vem a corroborar para o caráter altamente contraditório da recepção do oitocentista:

Na Crimeia, onde o horizonte é brilhante

Ele terminou seus jovens anos.

E se esconderam na urna sepulcral

Seu poderoso e forte talento,

E o ardor da alma cheia de amor,

E os sonhos da poesia sacra!...
В Крыму, гАе ярки неба своды,

Он мОАОдЫе кончил годы.

И скрылись в урне гробовой

Его та^ант могучий, сильный, И жар Ауши Аюбвеобильной, И сны поэзии святой!..

(BUNIN, Tradução nossa)

De fato, quando Nadson morreu na península, em Ialta, houve uma enorme agitação.

A morte [de Nadson] se tornou uma apoteose do amor geral pelo poeta: no caminho do corpo [a partir de Ialta] a São Petersburgo, ele foi acompanhado por uma multidão de fãs; o chefe da estrada de ferro Sudoeste, então futuro onipotente ministro [dos Transportes e das Finanças] Serguêi Iulievitch Vitte forneceu um vagão gratuito em Petersburgo após a missa de réquiem na Igreja da Trindade, os jovens carregaram o caixão até cemitério Volkov nos braços e sobre o túmulo soaram discursos, cada um mais ardente que o outro. (Ivanova, 1987 p. 14 apud KOLEROV, 2018 p. 15 , tradução nossa)

De inclinação totalmente diversa a Búnin, Vladímir Ilitch Lênin era outro entusiasta da obra de Nadson. Em sua "biografia intelectual" do líder revolucionário, Tamáz Krausz menciona a seguinte carta de Nadejda Krupskaia a partir de Cracóvia, em dezembro de 2013, à mãe de Lênin, em Vologda, após um concerto de um quarteto de cordas de Beethoven:

Por algum motivo, a música nos deixou terrivelmente mal, apesar de uma conhecida nossa [ela se refere a Inessa Armand], uma excelente musicista, ter ficado em êxtase com ela... Se há qualquer coisa pela qual ansiamos aqui é boa literatura. Volódia [Vladímir] praticamente decorou Nadson e Nekrássov e um velho tomo de Anna Karênina está sendo lido pela centésima vez. (KRAUSZ, 2015, tradução nossa) 
Em sua recente obra Arkheologuia russkogo polititcheskogo idealizma 1900-1927 (A arqueologia do idealismo político russo 1900-1927), o historiador Modest Kolerov lança as bases para a hipótese, com base em documentos de arquivo, de que a tríade literária composta por Vsevolod Garshin (1855-1888), Nadson e Anton Tchékhov (1860-1904) - este, com algum atraso - formava o principal alicerce da juventude revolucionária a ganhar uma ideia de pertencimento, de nach. Assim, no início do século XX, quando a reação política, dando continuidade à repressão, já não podia conter o patente renascimento social e deu os primeiros passos em direção a uma nova liberalização, os escritores da época anterior mais populares, mais publicados e mais exitosos comercialmente eram, postumamente, Garchin e Nadson, e, ainda vivo, Tchékhov, que iniciara sua carreira como escritor na década de 1880: "Todos os três eram relacionados pelos críticos, igualmente, aos heróis da época da reação política e da aflição civil $^{5}$, fosse como seus representantes, como aqueles que a descreviam, ou ainda como os que a expressavam." (KOLEROV, 2018 p. 15).

Assim, apesar de muito divididas as opiniões russófonas nadsonianas, a crítica internacional pouco menciona o outro lado do fenômeno. Nosso Otto Maria Carpeaux, por exemplo, escreveu:

Heinianos sentimentais, havia-os em toda a parte, corrompendo o gosto do público; como Nadson, infelizmente o poeta russo mais lido da segunda metade do século XIX. Esse tipo heiniano de poeta tuberculoso, morrendo de fome na mansarda, queixando-se com ironia amarga, esse tipo ainda está presente em Laforgue; e algo de ironia heiniana existe na poesia satírica de ingleses e norte-americanos modernos, em Auden, Wallace Stevens, Ransom. (CARPEAUX, 2008 p. 1694)

Um dos poemas que verto abaixo, Porá, chegou a ser musicado por Serguêi Rachmaninoff (Op.14, No. 12). Além disso, outros versos seus foram incorporados e musicados por Rachmaninoff, César Cui etc. O autor foi mencionado e teve seus versos reproduzidos por nomes como Pável Florênski e Merejkovski. Como escreveu o pesquisador Charles Bedford (1957, p. 161), "Nadson gozava

5 Grajdânskaia skorb ou "aflição civil" é uma expressão literária irônica que se utiliza para designar "reclamações pessimistas, queixumes da intelligentsia". Na crítica russa, o epíteto geralmente caracteriza as obras de prosaístas e poetas das décadas de 1840-1870, "que recebiam de forma dolorosa e sensível a realidade que os circundava, mas se sentiam impotentes para mudar a situação corrente das coisas". (Grajdanskaia skorb. Bolchoi slovar russkikh pogovorok, [s.d.]) 
da simpatia da juventude radical da década de 1880. Sua linguagem era a deles; ele dizia generalidades; e ele era idealista, melancólico e individualista."

Mas Nadson não era apenas isso. Considerado poeta cívico por alguns, como Bedford (idem, p. 161), ele simpatizava com os feitos de autosacrifício do grupo Narodnaia volia (em português, Vontade do Povo), grupo revolucionário formado em 1879 e responsável pelo ataque terrorista que resultou na morte de Aleksandr II. Como lembra Kulikov (1995, p. 134), os poemas de Nádson Mratchnaia moia tiurma (Minha prisão sombria), Ni zunka v ugriumoi tichi kazemata (Nem sequer um som do silêncio lúgubre da casamata), Ti dlia kogo echio i den v lutchakh sïaet (Você para quem o dia ainda brilha em raios) reproduzem todo o sofrimento e a força da alma das vítimas dos processos do Vontade do Povo. Em 1885, Nádson, inspirado pela figura da revolucionária Vera Figner e impressionado com o processo "Décimo Quarto" pelo qual ela foi julgada, escreveu o poema Po smutnim priznakam, dostupnim dlia nemnoguikh (Por sinais obscuros, acessíveis a poucos), que ecoa diretamente o poema em prosa de Turguêniev Porog (Limiar).

Enfim, seguem abaixo propostas de tradução ${ }^{6}$ de dois poemas deste inegável ídolo da intelligentsia de fin de siècle. São eles: Porá (É hora!) e Drug moi, brat moi, ustalyi, stradaiuschii brat (Meu amigo, meu irmão, cansado e sofredor irmão). Noto que, como work, in progress, nesta versão ao português busquei ater-me à semântica e à rima, sem dedicar-me à métrica.

\section{É hora!}

É hora! Manifeste-se, profeta! Com toda a força inquietante,

Com toda a força do amor a ti clamamos!

Veja como desamparados estamos na luta torturante,

Veja como avelhentamos, como cansamos! É agora ou nunca!... A consciência desvanece, A vergonha se extingue, a moral adormece. Nem faísca ao redor, Apenas o desprezível sua voz engrandece...

\section{Пора!}

Пора! Явись, пророк! Всей силою печали, Всей силою Аюбви взываю я к тебе! ВзгАяни, как Аряхлы мы, взгляни, как мы устали,

Как мы беспомощны в мучительной борьбе!

Теперь - иль никогда!.. Сознанье умирает, Стыл гаснет, совесть спит. Ни проблеска кругом, ОАно ничтожество свой голос возвышает... 


\section{Meu amigo, meu irmão, cansado e sofredor irmão}

Meu amigo, meu irmão, cansado e sofredor irmão,

Quem quer que seja, não deixe a alma rebaixada. Que reinem soberanos a mentira e o mal Sobre a terra de lágrimas lavada.

Que se arruíne e vexe o sagrado ideal

E o sangue inocente corra:

Acredite, chegará a hora em que perecerá o Baal E à terra o amor recorra!

Não com coroa de espinhos, nem sob o jugo das correntes,

Não com uma cruz nos ombros arqueados.

Ao mundo ele torna em sua força e glória inerentes,

Com a felicidade nas mãos em fachos iluminados.

E não haverá na terra nem lágrimas, nem animosidade,

Nem túmulos sem cruzes, nem escravizados,

Nem necessidade, a desesperançada e mortal necessidade,

Nem a espada e nem os castigados?

Ah, meu amigo! Não é sonho esse regresso

iluminado,

Nem apenas esperança vazia:

Veja, a maldade ao redor já oprime demasiado,

A noite ao redor já é por demais sombria!

O mundo fartar-se-á de suplícios, com o sangue

sufocará,

Ficará extenuado da insana luta:

E rumo ao amor, a um sincero amor, levantará

Os olhos cheios de uma aflita súplica!

Semion Nadson, 1880

О мой Аруг! Не мечта этот светлый прихоА,

Не пустая надежАа одна:

Оглянись, - зАо вокруг чересчур уж гнетет, Ночь вокруг чересчур уж темна!

Мир устанет от мук, захлебнется в крови, Утомится безумной борьбой -

И поднимет к Аюбви, к беззаветной Аюбви, Очи, полные скорбной мольбой!..

Trad.: Marina Darmaros

7 Aqui, o autor usa o termo позорный столб [pozornyi stolb], que se traduz literalmente por "poste da vergonha", e poderia ser substituído no texto por "pelourinho", elemento que era altamente difundido pela Europa na Idade Média. Em português, o termo "pelourinho" deriva de pilloria, do latim, que pode ter sido o diminutivo de pila (poste, barreira de pedra) e também deu origem à palavra em inglês pillory. Optamos por utilizar aqui o resultado do pelourinho (castigados) em prol da rima. 


\section{Referências bibliográficas}

BEDFORD, C. H. (1957). D. S. Merezhkovsky: The Forgotten Poet. The Slavonic and East European Review, 36(86), p. 159-180.

BUNIN, Ivan. Nad moguiloi Nadsona. [s.d.]. Disponível em: https://ilibrary.ru/ text/3826/p.1/index.html. Acesso em: 10 jul. 2020.

CARPEAUX, Otto Maria. História da Literatura Ocidental (Vol. III). Brasília: Edições do Senado Federal, 2008.

DIAS, Daniele Pampanini. O trabalho com literatura no primeiro ano do ensino fundamental: modos de participação das crianças na elaboração do sentido estético. Dissertação apresentada ao Programa de Pós-Graduação em Educação da Faculdade de Educação da Universidade Estadual de Campinas. Unicamp, Campinas, 2017.

FRIEDBERG, M. (1984). The Jewish Search in Russian Literature. Prooftexts (International Jewish Writing: From the Bellagio Conference by Indiana University Press), 4(1), p. 93-105.

GLAZOVA-CORRIGAN, Elena. Mandel'shtam's poetics: a challenge to postmodernism. Toronto: University of Toronto Press, 2000.

GRAJDANSKAIA skorb. Bolchoi slovar russkikh pogovorok. [s.d.]. Disponível em: https:// dic.academic.ru/dic.nsf/proverbs / 42480/\%D0\%93\%D1\%80\%D0\%B0\%D0\%B6\%D0\% B4\%D0\%B0\%D0\%BD \%D1\%81\%D0\%BA\%D0\%B0\%D1\%8F. Acesso em: 14 jul. 2020.

HETÉNYI, Z. (2008). The Concept of Russian-Jewish Literature and its Ambiguities a Theoretical View. In In a Maelstrom: The History of Russian-Jewish Prose, 1860-1940. Central European University Press.

KOLEROV, Modest. Arkheologuia russkogo polititcheskogo idealizma (1900-1927). Moscou: Nezavissimi Alians, 2018.a

KRAUSZ, Tamáz. Reconstructing Lenin: An Intellectual Biography. Nova York: Monthly Review Press, 2015. Kulikov, B. P. (1995).

MARQUES, Priscila Nascimento. O Vygótski Incógnito: Escritos Sobre Arte (1915-1926). Tese de doutorado apresentada ao Programa de Literatura e Cultura Russa da Universidade de São Paulo. Universidade de São Paulo, São Paulo, 2015.

MAIAKÓVSKI, Vladímir. O Percevejo. São Paulo: 34, 2009.

MANDELSTAM, Ó. O rumor do tempo. São Paulo: 34, 2019.

NADSON, Semion Iakovlevitch. Polnoie sobranie sitkhotvorenii. São Petersburgo: Akademitcheskii proekt, 2001.

RIBEIRO, Juscelino Batista. Estética e Política na Dramaturgia de Vladimir Maiakóvski. Dissertação de mestrado apresentada ao programa de Pós-graduação em História da Universidade Federal de Uberlândia. Uberlândia, 2001.

RUSSKIE pissateli i narodovoltcheskoe dvijenie. Sotsialnie i Gumanitarnie Nauki. Otetchestvennaia $i$ Zarubejnaia Literatura, 7, p. 121-136.

THE Poet of Despairing Hope. (1937). The Slavonic and East European Review, 15(45), p. 680-687. 